\title{
The influence of environmental factors and heavy metals in the soil on plants' growth and development
}

\author{
Nicoleta Alexandra Vanghele ${ }^{1}$, Mirabela Augustina Pruteanu ${ }^{1, *}$, Ancuța Alexandra Petre ${ }^{1}$, \\ Andreea Matache ${ }^{1}$, Dumitru Bogdan Mihalache ${ }^{1}$ and Mariana Mădălina Stanciu ${ }^{1}$ \\ 1) The National Institute of Research - Development for Machines and Installations designed to \\ Agriculture and Food Industry - INMA Bucharest
}

\begin{abstract}
Plants need certain conditions that represent their living environment. When the living environment provides the conditions required by the plant, it will grow and develop properly. The growth and development of plants involve environmental factors, which represent those constituent elements of the natural environment, which actively intervene in plants' life.

The present work shows the characteristics of an agricultural soil, contaminated with heavy metals $(\mathrm{Cu}, \mathrm{Pb}$ and $\mathrm{Zn})$ in different concentrations, which has been divided into pots, in which were thereafter planted vegetable seedlings (tomatoes, cucumbers, parsley, spinach, carrots, radishes). During the plants' growing time, the temperature and humidity of the air inside the greenhouse, as well as the humidity and $\mathrm{pH}$ of the soil, were monitored. The growth and the development of the plants under certain conditions were also tracked, until the end of the growing period. The results of monitoring the plants' growth and development are important in assessing the impact of the contamination over the soil and the plants.
\end{abstract}

Key words: environmental factors, heavy metals, soil, plants

\section{Introduction}

The main environmental factors that influence plants' growth and development are: light, temperature, water, air (carbon dioxide and oxygen), nutrients, $\mathrm{PH}$ and toxic substances. In some situations, environmental factors may become restrictive for growth and development processes, as they become harmful if they exceed certain limits and values or they cannot meet the necessary plants' requirements. All environmental factors are relatively equal in the process of growth and development, the insufficiency of one having negative repercussions on plants.

Systemic toxic pollutants, such as heavy metals, are particularly dangerous due to their long-lasting remanence in the soil, as well as to their intake by the plants and, implicitly, by humans. The main routes of the collection of metals by plants are the radicular takeover and the foliar takeover.

\footnotetext{
* Corresponding author: pruteanu_augustina@yahoo.com
} 
The cucumber (Cucumis sativus) is a vegetable plant, its optimum vegetation temperature is $25-28^{\circ} \mathrm{C}$, and the average temperature should not fall below $15^{\circ} \mathrm{C}$. The plants do not bear temperatures below $12^{\circ} \mathrm{C}$ or above $35^{\circ} \mathrm{C}$, values outside of this range stopping the growth.

They are light-loving plants, needing 12 hours of light per day, prefer aerated soil, rich in humus, permeable, with neutral or low acid $\mathrm{pH}$, with a humidity maintained at 70 $80 \%$.

The grown tomatoes come from the wild species of Lycopersicon esculentum var. cerasiforme, originated from the highlands of the Andes. They are annual plants that do not require special environmental conditions, in need of light and of a temperature that must not exceed $40^{\circ} \mathrm{C}$ nor be less than $10^{\circ} \mathrm{C}$. Tomatoes prefer medium-sized sandy-clay, clay-sandy soils, rich in humus, fertile, well-structured, with a good, deep drainage, with deep groundwater and a PH level between 5.5 and 7.0, and humidity between 40 and $70 \%$.

The spinach (Spinacea oleracea) is native in Central Asia; in Romania is cultivated in all areas. The spinach is a plant resistant to low temperatures, with the optimal growth temperature of $15-17^{\circ} \mathrm{C}$. In terms of light, spinach is a less demanding species, which grows well in spring, autumn and winter, when the light radiation is low. Water plays an important role in obtaining a rich foil, being necessary that the soil moisture is constant. The spinach prefers loose, wet soils, rich in humus, with a $\mathrm{pH}$ of 6.5-7.5 [1].

The parsley (Petroselinum crispum L) is native in the Mediterranean Sea area since the beginning of our era and can be cultivated both for the root and the leaves. The minimum germination temperature is $2-4{ }^{\circ} \mathrm{C}$, and the optimum vegetation temperature is $20^{\circ} \mathrm{C}$. Plants can withstand temperatures of up to $-30^{\circ} \mathrm{C}$. The water requirements are moderate, being resistant to drought but it is a light-loving plant. In terms of soil requirements, it is a demanding plant, preferring loose, light, deep and well-fattened lands, the ideal being the clay-sandy ones.

The carrot (Dancus carota $L$ ) is not exigent to heat; its preferred temperature is between 15 and $24^{\circ} \mathrm{C}$. Temperatures above $30^{\circ} \mathrm{C}$ are harder to tolerate, while the minimum temperature they endure is $3^{\circ} \mathrm{C}$. It prefers as much light as possible: being a long day plant, the more light it receives, the more it will develop harmoniously; same thing happens in the case of humidity. For the carrot, the ideal soil should be clay-sandy, sandy, alluvial, with a $\mathrm{pH}$ between 5.8-7 [2].

The radishes (Raphanus sativus $L$ ) are cold-resistant plants, adapting to temperatures between 2 and $17^{\circ} \mathrm{C}$. They are plants that need a lot of light and heat, and their favorite soils are those with light or medium texture, rich in humus, loosened, with a neutral $\mathrm{pH}$ and a good water retention capacity.

The plants capture and accumulate heavy metals, and this is due to certain factors such as: the climate, the concentrations of heavy metals within the soil, the nature of the soil in which they are grown, the atmosphere and the plants' maturity degree at their harvest $[3,4,5]$.

The heavy metals can be grouped into essential and non-essential metals. The essential heavy metals are $\mathrm{Co}, \mathrm{Cr}, \mathrm{Cu}, \mathrm{Fe}, \mathrm{Mn}, \mathrm{Ni}$ and $\mathrm{Zn}$ and are considered to be essential micronutrients, but they become poisonous when taken in excessive quantities. The nonessential heavy metals include $\mathrm{Pb}, \mathrm{Cd}$ and $\mathrm{Hg}$ and are highly toxic to living organisms $[6,7]$.

The long-term consumption of foods containing unsafe amounts of heavy metals can have repercussions on internal organs such as kidneys, liver, heart, and lead to various diseases over time such as chronical, kidney, cardiovascular, bone and nervous system diseases [8,9].

The main way of transferring the metals to the plant is by absorption through its roots. 
The main routes of the collection of metals by plants are the radicular takeover and the foliar takeover. The environmental factors that make up the plants' living framework are: light, temperature, water, air and culture substrate. The temperature is one of the most important climatic factors that influence the growth and development rate of the plants. It conditions the unfolding of fundamental processes that take place in plants (growth, photosynthesis, respiration, transpiration, absorption of water and of nutritional salts, etc.). The vital processes of plants can only take place at certain temperatures $[4,10]$. The growth and development of plants depends on the temperature in the atmosphere. The main source of heat of the atmosphere is the solar energy, from which plants absorb only a fraction of it. Each plant species has specific thermal requirements which causes the temperature to have a limiting action on their growth and development [10].

The paper presents the monitoring of soil parameters, atmosphere and plants (vegetables) along a vegetation cycle.

\section{Material and method}

The period of planting the vegetable seedlings was done between March and April 2018. Heavy metal infestation experiments carried out between March and September 2018 were done for a number of 7 plants (vegetables), specified in Table 1.

Table 1 - Classification of the vegetable plants studied [11]

\begin{tabular}{|l|l|l|}
\hline \multicolumn{1}{|c|}{ Group } & \multicolumn{1}{|c|}{ Common name } & Scientific name of the plant \\
\hline \multirow{2}{*}{ Cucurbitaceous vegetables } & Cucumber & Cucumis sativus $\mathrm{L}$ \\
\hline \multirow{3}{*}{ Solano-fruit vegetables } & Tomatoes & Lycopersicon esculentum \\
\cline { 2 - 3 } & Spinach & Spinacia oleraceea $\mathrm{L}$ \\
\cline { 2 - 3 } & Parsley & Petroselinum crispum $\mathrm{L}$ \\
\hline \multirow{3}{*}{ Root vegetables } & Carrot & Dancus carota L \\
\cline { 2 - 3 } & Parsley & Petroselinum crispum $\mathrm{L}$ \\
\cline { 2 - 3 } & Radishes & Raphanus sativus $\mathrm{L}$ \\
\hline
\end{tabular}

The figure \#1 shows aspects of the experimental research for the vegetable plants studied.

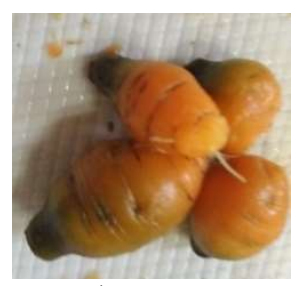

a) Carrot

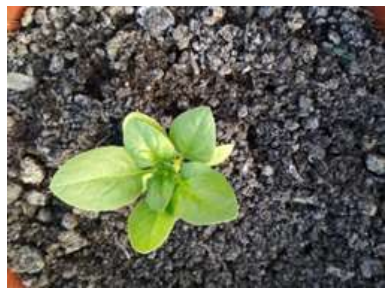

d) Spinach

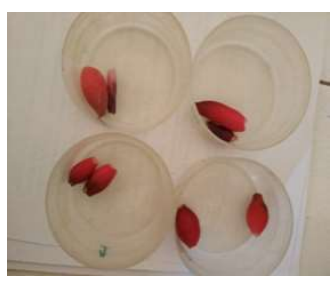

b) Radishes

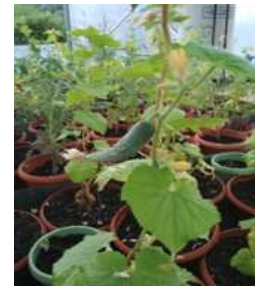

e) Cucumber

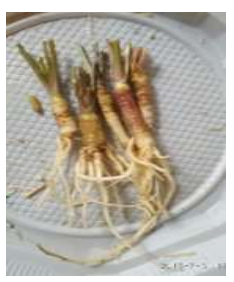

c) Parsley-root

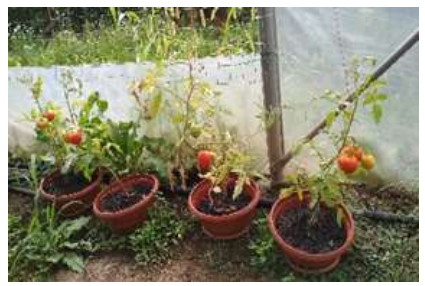

f) Tomatoes

Fig. 1. - The stage of vegetable development. 
All types of plants were planted in the soil and infested with the following four heavy metal concentrations: $1.5 \%, 3.0 \%, 4.5 \%, 6.0 \%$ and the heavy metals used were: copper, zinc, lead. In parallel, experiments were performed on plants grown in uninfested soil $(0 \%)$.

The concentrations specified in the study for the study of metals were chosen taking into account the limits allowed for them, an experiment performed on salads grown on contaminated soils with different concentrations to see the behavior of plants, but also the literature in the field.

Of the metals chosen in the work, lead is the most dangerous metal, so care must be taken with its content in both soil and plant, as it can seriously disrupt human health. In the paper, it is observed that at concentrations of $3 \%, 4.5 \%$ and $6.0 \% \mathrm{~Pb}$ exceeds the permissible imitation in the soil which is $50 \mathrm{mg} / \mathrm{kg}$.

In the experiments with vegetables the loading with heavy metal was carried out initially, when planting the seedlings, without supplementing it until the harvest.

The physico-chemical properties of the agricultural soil used in the experimental research were: $\mathrm{pH} 5.0-7.0$, total nitrogen $1.9 \%$, total phosphorus $0.5 \%$, total potassium $0.9 \%$, electrical conductivity 1.2 , humidity 14.7 .

The metals content of soils and plants was measured using a flame atomic absorption spectrometry

The granulometric analysis of the agricultural soil used in the experimental research was also carried out, the aspects during the work being shown in Figure 2 and the results obtained are shown in Figure 3.

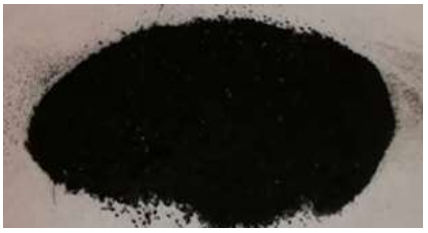

$<1.0 \mathrm{~mm}$

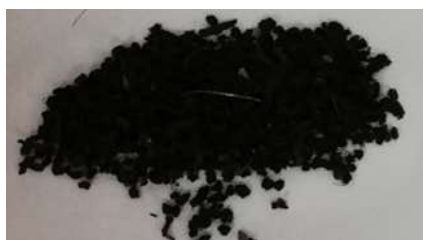

$3.16-5.0 \mathrm{~mm}$

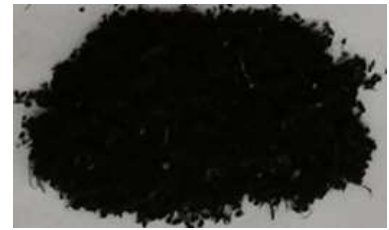

$1.1-2.0 \mathrm{~mm}$

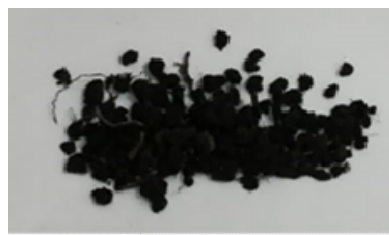

$5.1-8.0 \mathrm{~mm}$

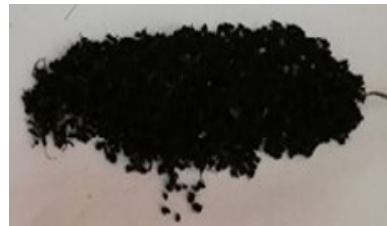

$2.1-3.15 \mathrm{~mm}$

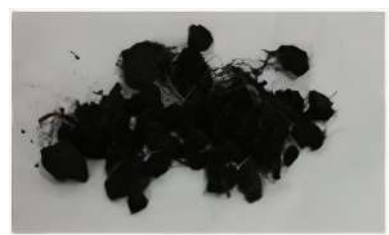

$>8.0 \mathrm{~mm}$

Fig. 2. Aspects during the screening of the agricultural soil used for the experimental tests

In the table 2 is presented the normal reference, alert threshold and intervention threshold values for soils of sensitive use listed in the Order no. 756/1997 of The Ministry of Waters, Forests and Environment Protection [12] and the maximum admitted values in leafy vegetables by FAO/OMS-Codex Alimentarius Commission, 2001 [13].

Table 2 - Heavy metal content $(\mathrm{Cu}, \mathrm{Zn}, \mathrm{Pb})$ in the soil/plant, $\mathrm{mg} \cdot \mathrm{kg}^{-1}$

\begin{tabular}{|l|l|l|l|}
\hline Soil Types /Plant types & $\mathbf{C u}$ & $\mathbf{Z n}$ & $\mathbf{P b}$ \\
\hline Normal values [12] & 20 & 100 & 20 \\
\hline Alert threshold [12] & 100 & 300 & 50 \\
\hline Intervention threshold [12] & 200 & 600 & 100 \\
\hline Maximum admissible values for leafy vegetables [13] & 73.3 & 99.4 & 0.3 \\
\hline
\end{tabular}




\section{Results and discussions}

Figure 3 showed the results obtained from the granulometric analysis of the agricultural soil used in the planting of vegetables.

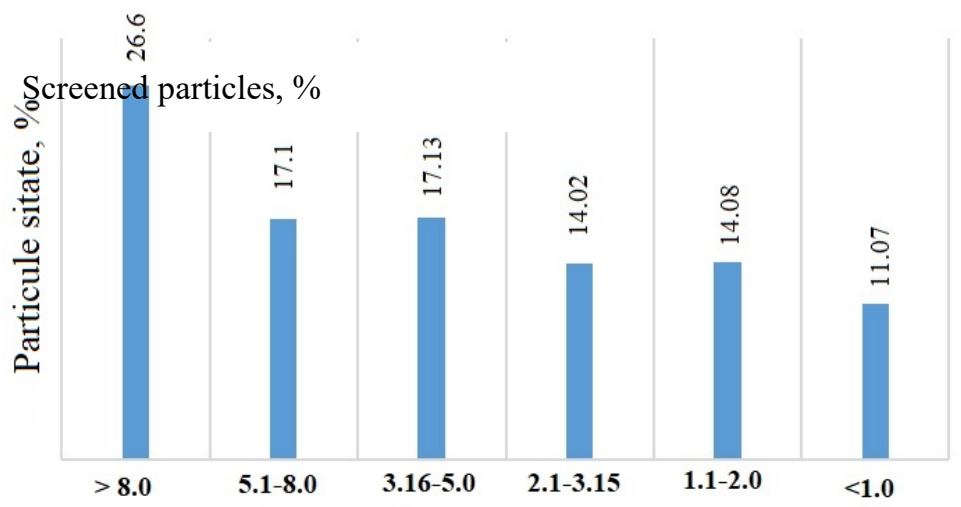

Dimensipaitecle size, $\mathrm{mm}$

Fig. 3. Granulometric analysis of soil used in experimental research

The soil parameters during the experimental research were: $\mathrm{pH}$ between 5.0-6.5 and soil moisture between $62.5-77.6 \%$.

The atmospheric conditions in the greenhouse during the growth of plants were: temperatures between $18-30{ }^{\circ} \mathrm{C}$ and air humidity between $45-80 \%$.

The following tables show the tracking of the evolution of the plants, in the case of soils contaminated with the three metals, namely $\mathrm{Cu}$ (table 3), $\mathrm{Pb}$ (table 4), $\mathrm{Zn}$ (table 5).

Table 3 - Plants subject to $\mathrm{Cu}$ infestation

\begin{tabular}{|c|c|c|c|c|c|c|c|}
\hline \multirow[t]{2}{*}{$\begin{array}{c}\text { Current } \\
\text { no }\end{array}$} & \multirow[t]{2}{*}{$\begin{array}{l}\text { Plant } \\
\text { name }\end{array}$} & \multirow[t]{2}{*}{$\begin{array}{l}\text { Vegetation period, } \\
\text { (days) }\end{array}$} & \multicolumn{5}{|c|}{$\begin{array}{l}\text { Harvest time (days) / } \\
\text { Categories of concentrations (\%) }\end{array}$} \\
\hline & & & $\mathbf{0}$ & 1.5 & 3.0 & 4.5 & 6.0 \\
\hline \multicolumn{3}{|c|}{ Quantity of metal in soil, mg/kg } & 17.6 & 58.9 & 267.2 & 525.1 & 680.8 \\
\hline 1 & Spinach & $40-50$ & 45 & 45 & 45 & 45 & 45 \\
\hline 2 & $\begin{array}{c}\text { Parsley } \\
\text { (leaf) }\end{array}$ & $30-35$ & 33 & 33 & 33 & 33 & 33 \\
\hline 3 & $\begin{array}{c}\text { Parsley } \\
\text { (root) }\end{array}$ & $70-145$ & 74 & 74 & 74 & 74 & 74 \\
\hline 4 & Radishes & 30 & 30 & 30 & 30 & 30 & 30 \\
\hline 5 & Carrot & 45 & 45 & 45 & 45 & 45 & 45 \\
\hline 6 & Cucumber & $38-50$ & 44 & 33 & 40 & 40 & 40 \\
\hline 7 & Tomatoes & $90-130$ & 73 & 73 & - & 93 & 80 \\
\hline
\end{tabular}

Table 4 - Plants subject to $\mathrm{Pb}$ infestation

\begin{tabular}{|c|c|c|c|c|c|c|c|}
\hline \multirow[t]{2}{*}{$\begin{array}{c}\text { Current } \\
\text { no }\end{array}$} & \multirow[t]{2}{*}{$\begin{array}{l}\text { Plant } \\
\text { name }\end{array}$} & \multirow[t]{2}{*}{$\begin{array}{c}\text { Vegetation period, } \\
\text { (days) }\end{array}$} & \multicolumn{5}{|c|}{$\begin{array}{c}\text { Harvest time (days) / } \\
\text { Categories of concentrations (\%) }\end{array}$} \\
\hline & & & $\mathbf{0}$ & 1.5 & 3.0 & 4.5 & 6.0 \\
\hline \multicolumn{3}{|c|}{ Quantity of metal in soil, $\mathrm{mg} / \mathrm{kg}$} & 6.75 & 48.7 & 84.7 & 117.7 & 285.2 \\
\hline 1 & Spinach & $40-50$ & 45 & 45 & 45 & 45 & 45 \\
\hline 2 & $\begin{array}{l}\text { Parsley } \\
\text { (leaf) }\end{array}$ & $30-35$ & 33 & 33 & 33 & 33 & 33 \\
\hline
\end{tabular}




\begin{tabular}{|c|c|c|c|c|c|c|c|}
\hline 3 & $\begin{array}{c}\text { Parsley } \\
\text { (root) }\end{array}$ & $70-145$ & 74 & 74 & 74 & 74 & 74 \\
\hline 4 & Radishes & 30 & 30 & 30 & 30 & 30 & 30 \\
\hline 5 & Carrot & 45 & 45 & 45 & 45 & 45 & 45 \\
\hline 6 & Cucumber & $38-50$ & 44 & 26 & 40 & 40 & 26 \\
\hline 7 & Tomatoes & $90-130$ & 73 & 106 & - & 80 & 95 \\
\hline
\end{tabular}

Table 5 - Plants subject to $\mathrm{Zn}$ infestation

\begin{tabular}{|c|c|c|c|c|c|c|c|}
\hline \multirow[t]{2}{*}{$\begin{array}{c}\text { Current } \\
\text { no }\end{array}$} & \multirow[t]{2}{*}{$\begin{array}{l}\text { Plant } \\
\text { name }\end{array}$} & \multirow[t]{2}{*}{$\begin{array}{l}\text { Vegetation period, } \\
\text { (days) }\end{array}$} & \multicolumn{5}{|c|}{$\begin{array}{c}\text { Harvest time (days) / } \\
\text { Categories of concentrations (\%) }\end{array}$} \\
\hline & & & $\mathbf{0}$ & 1.5 & 3.0 & 4.5 & 6.0 \\
\hline \multicolumn{3}{|c|}{ Quantity of metal in soil, $\mathrm{mg} / \mathrm{kg}$} & 39.8 & 202.7 & 534.8 & 921.7 & 1052.3 \\
\hline 1 & Spinach & $40-50$ & 45 & 45 & 45 & 45 & 45 \\
\hline 2 & $\begin{array}{c}\text { Parsley } \\
\text { (leaf) }\end{array}$ & $30-35$ & 33 & 33 & 33 & 33 & 33 \\
\hline 3 & $\begin{array}{l}\text { Parsley } \\
\text { (root) }\end{array}$ & $70-145$ & 74 & 74 & 74 & 74 & 74 \\
\hline 4 & Radishes & 30 & 30 & 30 & 30 & 30 & 30 \\
\hline 5 & Carrot & 45 & 45 & 45 & 45 & 45 & 45 \\
\hline 6 & Cucumber & $38-50$ & 44 & 26 & 40 & 26 & 29 \\
\hline 7 & Tomatoes & $90-130$ & 73 & 80 & 73 & 73 & 73 \\
\hline
\end{tabular}

Considering all the cases of vegetables grown with various concentrations of heavy metal in the soil, it was observed:

- a tendency to increase the amount of heavy metal accumulated in the plant, along with the increase of the initial concentration of heavy metal in the soil.

- the curves of variation of the concentration of heavy metal in plants that are monotonously increasing, appeared more often in the case of infestations with lead and zinc (for carrots, parsley and spinach), and less with copper;

- the curves of variation of the concentration of heavy metal in oscillating plants, appeared more often in the case of infestations with copper, and less with lead and zinc;

-in radishes the curves were increasing for all three metals, while in tomatoes the curves were oscillating for all three metals;

-in cucumbers, the monotonous increasing curves appeared in the case of infestations with copper and zinc, and less with lead.

\section{Conclusions}

Following the experiments on the seven plants we found that:

- All vegetables grown on uninfested soil $(0 \%)$, agricultural soil, reached plant maturity and were harvested in the optimal period.

- The spinach, parsley, radishes and carrots have reached vegetable maturity and have been harvested in the optimal period, at the same interval for all metals and concentrations.

- Cucumbers failed to reach plant maturity and were harvested earlier in the case of soil contaminated with $1.5 \%$ concentration, with $\mathrm{Pb}$ concentration $1.5 \%$ and $6 \%$ and $\mathrm{Zn}$ of concentration $1.5 \% ; 4.5 \%$ and $6 \%$.

- Tomatoes were the most affected plants from the ones tested; out of them, only those contaminated with $4.5 \%$ and $6 \%$ concentration and those contaminated with $\mathrm{Pb}$ concentration $6 \%$ were the only ones that reached plant maturity, and those that were contaminated with $3 \%$ concentration and $3 \%$ concentration $\mathrm{Pb}$, they were lost drying before harvesting. 
From the above mentioned, we can find that plants that have a shorter period of vegetation have survived and developed better in contaminated soil than those that have a longer vegetation period.

The research presented in the paper is important both for growers and consumers of fresh vegetables alike, but also for researchers, as this can be a starting point for future research in the field of heavy metal soil contamination and of vegetables, implicitly.

This work was supported by a grant of the Romanian Education and Research Ministry, through Programme 1 - Development of the national research-development system, subprogramme 1.2 - Institutional performance - Projects for financing excellence in RDI, contract no. 16PFE and by a grant of the Ministry of Agriculture and Rural Development, contract of sector financing, ADER type, no. 25.4.1 "Technology for obtaining biofertilizers and/or bioinsecticides, for ecological production systems".

\section{References}

1. N. Stan, N. Munteanu, T. Stan, Vegetables, vol III, "Ion Ionescu de la Brad" Publishing House, Iași, (2003);

2. Ruxandra Ciofu et al., Vegetable Treaty, “Ceres" Publishing House, Bucharest, (2004);

3. R. K. Sharma, M. Agrawal, F.M. Marshal, Heavy metals (Cu, Cd, Zn, Pb) contamination of vegetables in urban India: a case study in Varanasi, Environ. Poll., 154, pp. 254-263, (2008);

4. Sandeep G., Vijayalatha K.R., Anitha T. Heavy metal and its impact in vegetable crops, International Journal of Chemical Studies; vol. 7(1), pp. 1612-1621, (2019);

5. H. Zhou, W.-T. Yang, X. Zhou, L. Liu, J.-F. Gu, W.-L. Wang, J.-L. Zou, T. Tian, P.Q. Peng B.-H. Liao, Accumulation of heavy metals in vegetable species planted in contaminated soils and the health risk assessment, Int. J. Environ. Res. Public Health 13, 289, (2016); doi:10.3390/ijerph13030289;

6. I. P. Tripathi, N. Dwivedi, P. Shukla, M. Mishra and A. Tiwari, Heavy metals in vegetations from selected market sites in Chitrakoot, Satna M.P. India, International Journal of Current Research, Vol. 7 (01), pp. 11708-11711 (2015);

7. Sandeep, G., Vijayalatha, K.R., Anitha, T., Heavy metals and its impact in vegetable crops. Int. J. Chem. Stud. 7 (1), pp. 1612-1621, (2019);

8. C. L. Jarup. Hazards of heavy metals contamination, British Med. Bull., 68, pp.167182, (2003);

9. S. Kamran, A. Shafaqat, S. Hameed, S. Afzal, F. Samar, B. S. Muhammad, A. S. Bharwana, M. T.Hafiz, Heavy metal contamination and what are the impacts on living organisms, Greener Journal of Environmental Management and Public Safety, vol. 2 (4), pp. 172-179, (2013);

10. V. Iordache, E. Cojoc, Modeling the bioaccumulation of heavy metals in crop plants in copsha Mica area, University of Bucharest, (2019), http://www.cesec.ro/pdf/CojocEmilia2011.pdf

11. S. Bruma, Organic vegetable cultivation technologies, No. 2, "Terra Nostra" Publishing House (2004);

12. *** Order no. 756/1997 of the Ministry of Waters, Forests and Environment Protection.

13. *** FAO/WHO, Codex Alimentarius Commission, 2001. 